\title{
Grandparents' childhood exposures and religious belief in their granddaughters: possible transgenerational associations
}

Jean Golding*, Steven Gregory, Kate Northstone, Marcus Pembrey, Genette Ellis, Sarah Watkins, Yasmin Iles-Caven, Matthew Suderman

Population Health Sciences, Bristol Medical School, University of Bristol, Bristol, UK.

*Correspondence to: Professor Jean Golding: jean.golding@bristol.ac.uk

\begin{abstract}
The prevalence of religious belief has fallen dramatically. A possible reason is that environmental exposures to previous generations are involved, e.g., evidence of an association between childhood exposures of grandparents and outcomes in their grandchildren including obesity, autistic traits, and survival have been reported. Generally, the associations between the grandparent's exposure and grandchild's outcome varied with sex of grandparent, his/her age at exposure and sex of the grandchild.

Using data collected by the Avon Longitudinal Study of Parents and Children (ALSPAC) we investigate whether exposures such as smoking and/or traumatic events experienced by any of the grandparents are associated with the likelihood that their adult grandchildren have a religious belief. We show that the granddaughters (but not the grandsons) were more likely to have reported such a belief if one of their maternal grandparents had experienced traumatic events pre-puberty (age 6-11), or their paternal grandmother had experienced such events in adolescence. Conversely if their maternal grandfather had started smoking regularly during childhood or their paternal grandmother had smoked prenatally, the granddaughter was substantially less likely to be a believer. These associations were mutually independent and not explained by demographic factors. They may account for a small proportion of the fall in prevalence of religious belief over time, but the association needs confirming in other studies.
\end{abstract}

Keywords: ALSPAC; religion; spirituality; belief; intergenerational; grandparent; childhood traumas; grandparental smoking. 


\section{Introduction}

There is a striking decline in religious and spiritual beliefs in the populations of many Western countries. At one stage it was thought that the United States showed less of a reduction and generally behaved differently from Europe, but there is now evidence that the patterns of reduction are very similar $[1,2]$. The reasons for such a decline are not obvious, and likely to be multifactorial. One obvious possibility concerns the impact of various members of the family. However, Brauer [1] showed that although the frequency of religious service attendance is largely explained by changes in family dynamics, he found that selfrated religiosity seems to be declining across cohorts in ways that are not attributable to parent characteristics or parent-child relationships.

To unravel some of the features that may have contributed to the decline we analysed data from a large multigenerational cohort, the Avon Longitudinal Study of Parents and Children (ALSPAC), to determine background features of the cohorts of parents and their offspring which are associated with religious/spiritual belief. In this, the first paper in this series of aetiological investigations, we address the question as to whether there may be an epigenetic mechanism involved. Twin studies have indicated that religiosity and/or spirituality can be inherited [e.g. 3, 4]. There is now increasing evidence that inheritance can not only involve the DNA itself, but that non-genetic inheritance also exists [5]. This often involves processes whereby environmental exposures to previous generations contribute to outcomes in unexposed descendants. For example, smoking (particularly pre-pubertal onset of regular smoking in grandfathers and prenatal smoking in grandmothers) has been shown to be associated with outcomes in grandchildren as varied as obesity, asthma, and autistic traits $[6,7,8,9,10]$. In general, such outcomes have been marked by a changing prevalence over time. They have also been shown to be associated with ancestral exposures to toxins such as DDT pesticides [11], and stressors such as famine and war [12, 13].

Since the prevalence of spirituality/religiosity shows a dramatic change over time, in this paper we investigate whether there is any evidence indicating possible intragenetic or transgenetic associations involving either exposures to cigarette smoking or traumatic events in previous generations. Since other studies have shown the pre-pubertal ages to be of particular importance [e.g., 13,14], we have ensured that such apparently susceptible ages of the grandparents at exposure are considered in the analyses.

\section{Results}

\section{The Granddaughters' Religious Beliefs}

\section{Unadjusted associations}

Of the 12,351 pregnant women who answered the question on religious belief, $50 \%$ responded positively [15]. The ways in which the prevalence of such belief varied according to demographic features of each of her four grandparents is shown in Table 1. Of the seven demographic features, the only ones with appropriate $\mathrm{P}$ values to be taken forward for further analyses were: (a) the year of birth of the maternal grandmother (MGM) which showed a linear trend; the more recently the MGM had been born the less likely was her granddaughter to believe ( $\mathrm{P}<0.001)$; (b) the age of the MGM at the birth of the woman's mother: the older she was, the more likely her granddaughter was to believe $(\mathrm{P}=0.023)$; (c) the number of sisters the maternal grandfather $(\mathrm{MGF})$ had, the more likely his granddaughter to believe $(\mathrm{P}=$ 
0.014). There was an additional association with the year of birth of the PGF, but this was not associated with a linear trend and is considered likely to be a chance finding.

As a control assessment to determine whether these associations were specific to the woman's religious belief, we compared the same 28 features of her partners' grandparents with her belief (Supplementary Table 1). The years of birth of her partner's maternal grandparents were associated with her belief at $\mathrm{P}<0.05$, but the direction of the association was opposite to that found for the woman's maternal grandparents, and the linear trend was $\mathrm{P}>0.10$. We concluded that the associations found with the women's grandmothers were unlikely to be culturally determined.

Compared with the demographic features associated with the woman's biological grandparents (Table 1), the relationships with their environmental exposures show many more associations at $\mathrm{P}<0.05$ (Table 2). There were positive trends with the number of traumatic events occurring between the ages of 6 and 11 years of the MGM, the MGF and the PGM, such that the more events that had occurred the more likely the women were to have reported a religious belief. Similarly, there were positive associations with the number of traumatic events between ages 12 and 16 for MGM, MGF and PGF and religious belief in the granddaughters. There was also evidence of associations between ancestral smoking and the granddaughters' beliefs. Both the MGF starting to smoke regularly before age 16 and the PGM smoking during pregnancy were associated with reduced likelihood of religious belief in their granddaughters.

As with the demographic characteristics of the grandparents, we computed the proportion of women with a religious belief according to the environmental exposures of her partners' grandparents. In absolute contrast with Table 2 (where there were 10 associations at $\mathrm{P}<0.05)$, there was only one association at $\mathrm{P}<0.05$ and that was between the number of traumatic events that had occurred to his MGM before she was aged 6 and the granddaughter's belief (Supplementary Table 2).

\section{Adjusted associations}

For the statistical analyses to determine any independent associations with religious belief of the granddaughters, we examined the demographic and environmental features of each of the grandparents using stepwise regression.

(i) The maternal grandmother: The features of the MGMs that showed unadjusted associations with religious belief in the granddaughters at $\mathrm{P}<0.05$ were: (a) her year of birth; (b) her age when the mother was born; (c) no. of traumatic events aged <6; (d) no. of traumatic events at ages 6-11; (e) no. of traumatic events aged 12-16 (Tables 1 and 2). Of these, the age variable was accounted for by the year of birth, and the traumatic events at ages $<6$ and $>11$ were secondary to the traumas at ages 6-11. Thus, the final model comprised just the two variables: traumas prepuberty and year of birth (Figure 1).

(ii) The maternal grandfather. The features of the MGFs that showed unadjusted associations with religious belief in the granddaughters at $\mathrm{P}<0.05$ were: The unadjusted associations at $\mathrm{P}<0.05$ were (a) the number of sisters he had; (b) no. of traumas aged 6-11 years; (c) no. of traumas aged 12-16; (d) started smoking regularly before age 17 . Of these, the no. of traumatic events aged 6-11 
predominated over those occurring at ages $12-16$ but smoking regularly aged $<17$ was independently associated. These two variables comprised the final model.

(iii) The paternal grandmother. There were no demographic variables related to the PGM which had an unadjusted association at $\mathrm{P}<0.05$ with the granddaughters' religious belief. However, there were three environmental associations: (a) no. traumatic events aged 6-11; (b) started smoking regularly before age 17; (c) smoked in the pregnancy resulting in the birth of the woman's father. Of these, backward stepwise analysis resulted in just the number of traumatic events aged 611 remaining in the model. Conversely, forward stepwise analysis resulted in the pregnancy smoking variable entering but not the traumas; however, the numbers in this final model were considerably smaller than the previous one $(\mathrm{n}=1030 \mathrm{v}$. 1925).

(iv) The paternal grandfather. Only one variable concerning the PGF was associated with religious belief in the granddaughter - and that concerned the number of traumatic events he had been exposed to aged 12-16. When offered to the factors associated with his wife (PGM), his exposure did not contribute independently to his granddaughter's religious belief.

\section{The Grandsons' Religious Beliefs}

The proportion of men reporting a religious belief (37\% of 9789 fathers) at the time of pregnancy in 1991-2 was considerably lower than their female partners (50\%). The only notable unadjusted associations with the demographic features of their grandparents concerned associations with the age of their grandfathers at the time of birth of their parents: the older the grandfather was the more likely his grandson to have a religious belief (Table $3)$.

For the possible environmental exposures, there was evidence of associations with early childhood traumas (<6 years) in the MGM, the MGF and the PGF; such early exposures to each of these grandparents being associated with a lower rate of religious belief in their grandsons, but no associations with traumatic events later in childhood. There were no associations with smoking at the $\mathrm{P}<0.05$ level, but it is of interest that the grandsons of the grandparents who had started smoking prior to age 17 all had a lower prevalence of belief. There was little indication of any difference in religious belief of the grandsons if their grandmothers had smoked during pregnancy, although the proportion of grandsons with such a belief were lower than those of grandsons of mothers who did not smoke in pregnancy (Table 4). We have not undertaken further analyses due to small numbers (Supplementary Table 2).

\section{Patterns of association}

Comparison of the unadjusted results in Tables 2 and 4 indicate that, for associations with the numbers of traumatic events in the childhoods of their grandparents, the ages of 6-11 and 12-16 predominate for the granddaughters, whereas for the grandsons, it is the number of traumatic experiences aged $0-5$ that are the only significant associations at $\mathrm{P}<0.05$.

The types of individual traumatic exposures to the grandparents which were associated at $\mathrm{P}<0.10$ are shown in Table 5. Of the 15 associations of the granddaughters' 
religious beliefs with a grandparent's traumatic experience, $13(87 \%)$ showed an odds ratio greater than 1 ; i.e., the granddaughters were more likely to have a religious belief if their grandparents had such a history. In contrast, of the 14 associations of religious belief among the grandsons with traumatic experiences in their grandparents' childhoods, only $3(21 \%)$ demonstrated odds ratios greater than 1 , thus indicating that the grandsons were less likely to have a religious belief if their grandparents had such a history.

\section{Discussion}

This is the first study to our knowledge to have assessed whether there is any intra- or trans-generational evidence for religious beliefs being associated with features of the ancestral environment. We have taken grandparent smoking and traumatic events in their childhoods as our exemplars of possible environmental factors that might have such an effect, since there is evidence that these exposures to grandparental ancestors have been associated with different outcomes in their grandchildren. For example, grandmothers' smoking during pregnancy has been demonstrated to be associated with several different outcomes in the grandchildren [6]; early onset of regular smoking of the grandparent prior to conception is associated with obesity in the grandchild [12], and a grandparent's exposure in midchildhood to famine is associated with long-term survival and improved mental health in their grandchildren $[13,14]$. We hypothesised that if there was a relationship between religious belief in the grandchildren and exposures of grandparents to environmental factors, the associations would be likely to be associated differently according to the sex of the index grandchild as well as of the type of grandparent. This has been borne out in the analyses we have presented.

The results are complex. We have shown that the religious belief of the granddaughters (but not the grandsons) was positively associated with the number of traumatic circumstances in the childhoods of three of their grandparents (MGM, MGF and PGM) at ages 6-11; conversely the number of traumatic experiences the grandparents (MGM, MGF and PGF) had experienced aged $<6$ years was associated with an indication of reduced likelihood of religious belief in the index grandsons (but not the granddaughters).

It is notable that there were few demographic features of the grandparents that were associated with religious belief in their grandchildren. The one exception concerned the years of birth of the maternal grandmother which was strongly associated with religious belief of her granddaughter such that the more recently the MGM had been born, the less likely the granddaughter was to believe (Figure 1). This was not explained by social characteristics or by the age of the MGM when her daughter was born; nor was it found for the other grandparents.

Using a control experiment associating the characteristics of the grandparents of the granddaughter's partner with her own beliefs, we showed that there were associations with the years of birth of his MGM and MGF, but they were in the opposite direction - the more recently they had been born, the greater the likelihood that the granddaughters would have a religious belief. This suggests that the association of the year of birth of the MGM of the granddaughter with her own religious belief was probably not due to an overall trend in reducing prevalence in belief in general. 
Cigarette smoking of the MGF did demonstrate some associations with the religious belief of his granddaughter such that if he had started smoking in childhood ( $<17$ years), she (but not his grandson) would be less likely to believe. There was also a possible association with PGM smoking in pregnancy with the granddaughter which remained in the analysis when forward, but not backward, stepwise analyses were carried out (see Figure 1).

\section{Putting the results in context}

The first study to demonstrate associations between traumatic incidents occurring to grandparents in childhood being associated with outcomes to the grandchildren involved the occupants of the rural town of Överkalix on the edge of the Arctic Circle in Sweden. The authors showed that exposure of the occupants to famine during what the authors called the slow growth period, but which we would more accurately call pre-puberty, was associated with mortality and survival of their adult grandchildren [12]. The results were related to the harvest records and showed associations with very poor and excessively good harvests which were specific to the sex of the grandparent and to that of the grandchild. These results were validated by a larger study in Uppsala [16]. In parallel, van den Berg and Pinger [13] analysed data on the grandchildren whose grandparents had been exposed to a major famine in Berlin, and demonstrated that if the paternal grandfather had been exposed pre-puberty, then his grandsons (but not granddaughters) had better mental health than expected, but if the maternal grandmother was exposed pre-puberty, then her granddaughters (but not grandsons) had better mental health. These results raise the question as to whether these associations are with poor nutrition, or with the stress that will have been associated with famine, especially during a war which was the case in Berlin. In the present ALSPAC study, there were few grandparents who were reported as having insufficient food during childhood [17]. However, we have shown that exposure of the maternal grandparents to one or more traumas in mid or late-childhood was associated with increased likelihood of religious belief in the granddaughters (but not the grandsons). Conversely there was a suggestion that exposures in early childhood were associated with reduced likelihood of religious belief in their grandsons (but not granddaughters).

Examples of relationships between onset of smoking in childhood and later outcomes have, so far, concentrated on a single generation. Several different cohorts have shown that onset of regular cigarette smoking in childhood is associated with increased obesity and asthma in the next generation [e.g., 7, 11]. We believe this to be the first study to examine associations in the grandchildren of grandparents who started smoking regularly in childhood.

In contrast, several studies have considered the possible effects of a grandmother smoking in pregnancy on the grandchild. The results, summarised for ALSPAC publications to date in Table 6, indicates that when the MGM smokes prenatally, the grandson is more likely to be associated with outcomes, whereas if the PGM smokes during pregnancy, the associations are with the granddaughter's outcomes. This study shows a similar association with the PGM smoking by demonstrating a reduced chance of the granddaughter having a religious belief.

This accumulating evidence of smoking by a grandmother in pregnancy being associated with a sex-specific outcome is now complemented by results of DNA methylation in the maturing grandchild (age 15-17) that indicate different associations depending on the type of grandmother, and the sex of the grandchild [18]. 


\section{Religious belief or Spirituality - What's in a name?}

There is much confusion as to the difference between religious belief and spirituality. For this study we have used the positive answer to the question 'Do you believe in God or some Divine power?'. Elsewhere we show that the answers to this question are more closely correlated with answers to the question 'To what extent do you consider yourself a religious person?' than to the question 'To what extent do you consider yourself a spiritual person?' (r $=0.642 \mathrm{v} .0 .468$ for the granddaughters and $0.684 \mathrm{v} .0 .517$ for the grandsons). Thus, the positive answer to the question on belief is somewhat more likely to be interpreted by the respondents as a religious rather than a spiritual belief.

\section{Strengths and Limitations}

The major strengths of the study concern the fact that it is based on a geographically defined population, rather than being based on individuals selected because of their faith or characteristics of their grandparents. Data on religious belief was collected in 1990-2 during the relevant pregnancy of the study mothers. There was no bias in selection (especially regarding characteristics of the grandparents) other than that the women had to be pregnant, have an expected date of delivery between April 1991 and December 1992 and live in the defined area. A further advantage to this study lies in the fact that information was available on the ancestors of the women's partners, and we were able to use the relationships between the exposures to the woman's partners' grandparents on the religious belief of the woman as a control.

There are, however, several limitations. (a) The population of pregnant mothers was asked to include their partners if they were happy to do so - but the ALSPAC study team had no way of contacting them other than via the mothers until approximately 20 years after the study had started when the men were enrolled in their own right. As a result, the response rate of the grandsons in these analyses is lower than that of the granddaughters, with consequent loss of statistical power. (b) The details collected on the grandparents of the pregnant women and their partners (i.e., the great grandparents of the ALSPAC study cohort) were not

collected from the study parents themselves (the grandsons and granddaughters) until 2018, by which time their response rate had dropped substantially due to mortality and loss to follow up. (c) The accuracy of response may be questionable, especially as many of the grandparents had died, and details of many of their childhoods with them. (d) The statistical power of the study was low for the grandparents of the grandsons and precluded more detailed statistical analysis. (e) We do not know the religious beliefs of the grandparents, so we cannot say whether a demographic factor or exposure was associated with an increase or decrease in religious belief across generations.

\section{Evidence that Religiosity is associated with biological differences}

The current demonstration of associations that may implicate biological mechanisms associated with religious belief may not be as far-fetched as it initially appears. There is growing evidence that religious and/or spiritual belief is associated with changes in the anatomy of the brain [19]. A systematic review concluded that, despite various problems in comparability across studies, the balance of evidence supported the conclusion that several brain regions are potentially associated with religiosity and/or spirituality including the medial frontal cortex, the orbitofrontal cortex and caudate [20]. A subsequent study of lesion 
network mapping identified a brain circuit centred on the periaqueductal grey (a brainstem region implicated in pain modulation and altruistic behaviour) as being associated with religion/spirituality [21].

\section{Biomarkers supporting the epigenetic consequences of smoking and traumatic exposures}

We have shown that the changes associated with potential epigenetic environmental exposures such as grandmother smoking in pregnancy are associated with changes in DNA methylation levels at specific $\mathrm{CpG}$ sites, including on the $\mathrm{X}$ chromosome of the grandchild [18]. There is also abundant evidence from experimental studies that traumatic events can have effects on the DNA methylome for several generations [e.g., 22]. Evidence in humans is less clear, although there are reports of changes in DNA methylation among offspring of holocaust survivors [23, 24], those exposed to famine [25] and to domestic violence [26].

\section{Conclusions}

The results of this study are tentative but intriguing and may point to some of the reduction in religious belief over the past 100 years as possibly being influenced by exposure to noxious chemicals as found in cigarette smoke. We suggest that further research should be carried out with other population-based studies to fill the gaps in regard to biological consequences of ancestral exposures to both cigarette smoking and traumatic events during childhood.

\section{Material and Methods}

\section{The study population}

The Avon Longitudinal Study of Parents and Children (ALSPAC) started to collect data from pregnant women in 1990. The eligible sample was defined as all women resident in a defined geographic area centred on the city of Bristol, whose expected date of delivery was between April $1^{\text {st }} 1991$ and December $31^{\text {st }}$ 1992. The overall aim of the study was to determine the environmental factors that might interact with genes to influence the health and development of their offspring [27]. Information concerning the backgrounds of the women and their partners was collected during pregnancy, and thereafter throughout the childhood, adolescence, and early adulthood of the offspring [28, 29, 30]. This paper is focused on the beliefs of these prospective parents, who we refer to as the granddaughters and grandsons.

Study data were collected and managed using REDCap electronic data capture tools hosted at the University of Bristol. REDCap (Research Electronic Data Capture) is a secure, web-based software platform designed to support data capture for research studies. [31] Please note that the study website contains details of all the data available through a fully searchable data dictionary and variable search tool: [https://www.bristol.ac.uk/alspac/researchers/our-data/]. Ethical approval for the study was obtained from the ALSPAC Ethics and Law Committee and the Local Research Ethics Committees (see [32] for full details)

Asked within questionnaires completed by the index men and women in 2017-18 were details of their four grandparents [17]. The nomenclature used is as shown in Figure 2, with MGM, MGF, PGM and PGF indicating maternal grandmother, maternal grandfather, paternal grandmother, and paternal grandfather respectively. Data collected about the 
grandparents included demographic details as well as potential epigenetic associations assessed by their smoking history and possible traumatic events that occurred during their childhoods.

\section{Measure of religious belief}

During the study pregnancies, each index parent was asked to complete a questionnaire which included a variety of questions on religion, spirituality, belief, and religious behaviour [15]. For this study we use a positive response to the question: 'Do you believe in God or some divine power?' to denote religious belief.

\section{Data concerning environmental exposures}

In regard to smoking, the grandchildren were asked (i) whether their grandparents had started smoking before the age of 17, and (ii) whether their grandmother had smoked when pregnant with the individual who was to become their parent.

For each of these grandparents, questions were asked concerning whether they had: (a) suffered from a serious illness; (b) attended boarding school; (c) been taken into care by family or (d) by others; (e) had been in a war situation; (f) became a refugee; ( $\mathrm{g}$ ) been subjected to violence directly or (h) whether there was violence in their home; (i) not enough to eat at times or (j) an unhappy childhood. In addition, during their childhood whether any of the following had occurred to their parents including $(\mathrm{k}, \mathrm{l})$ whether either had died; $(\mathrm{m}, \mathrm{n})$ been seriously ill; $(\mathrm{o}, \mathrm{p})$ been in a war situation or $(\mathrm{q}, \mathrm{r})$ became a refugee. Finally, they were asked (s) to describe any other major events or provide additional comments concerning their ancestor's childhood. For each of these 19 questions, multiple responses were allowed: yes aged 0-5; yes aged 6-11; yes aged 12-16; yes, but age not known; no. We have used the number of different events in each age period as an exposure of interest.

\section{Potential confounders}

For each grandparent the following data were collected: whether they were born in England or elsewhere; their year of birth; their age at the birth of the parent of the index generation, their social class based on their occupation; the number of brothers and sisters they had and whether they were firstborn.

\section{Statistical analyses}

This is an exploratory analysis to determine whether there are any indications that there may be an epigenetic aetiology to some aspects of religiosity. The outcome measure is the presence of a religious belief in the grandchild. Numbers of individuals available for analysis are shown in Supplementary Table 4. The numbers of granddaughters with data available were greater than the numbers of grandsons; the numbers relating to the maternal grandparents were greater than those relating to the paternal grandparents and, apart from social class (as women did not tend to work in the generation of interest), the numbers available for particular features were greater for grandmothers than grandfathers. Consequently, the statistical power is greatest for the characteristics of the maternal grandparents of the granddaughters.

Separate sets of analyses were undertaken for the grandsons and granddaughters. The initial analyses first assessed the associations between the potential confounders and the 
outcomes, and secondly the associations with the possible environmental exposures. Since the numbers of traumatic events occurring at any one age group tended to be dominated by those with no events, $\mathrm{P}$ values were also calculated for none v. any. Factors that were significant at the $\mathrm{P}<0.05$ level for any one type of grandparent were selected for further analysis. Because there was considerable multi-collinearity between some of the variables, backwards stepwise logistic regression was used to determine those factors that were most likely to be independently associated with each grandchild. As a check on these results, the analyses were repeated using forwards stepwise analyses, and any differences were documented.

Sensitivity analyses were undertaken to determine the specificity of the findings. For example, as a comparison with the findings between the woman's religious beliefs and characteristics of her grandparents we compared these with associations found between her religiosity and her male partners' grandparents' characteristics. If they proved to be similar this would indicate that the initial results were likely to be due to cultural similarities.

\section{Acknowledgements}

We are extremely grateful to all the families who took part in this study, the midwives for their help in recruiting them, and the whole ALSPAC team, which includes interviewers, computer and laboratory technicians, clerical workers, research scientists, volunteers, managers, receptionists, and nurses.

\section{Funding}

The UK Medical Research Council and Wellcome (Grant ref: 217065/Z/19/Z) and the University of Bristol provide core support for ALSPAC. A comprehensive list of grant funding is available on the ALSPAC website (http://www.bristol.ac.uk/alspac/external/documents/grant-acknowledgements.pdf ); This research was made possible through the support of grants from the John Templeton Foundation (60828 and 61917). This publication is the work of the authors and Jean Golding will serve as guarantor for the contents of this paper. The opinions expressed in this publication are those of the authors and do not necessarily reflect the views of the John Templeton Foundation.

\section{Conflicts of Interest: None}

\section{References}

1.Brauer, S. G. (2019). Cohort Succession, Intergenerational Transmission, and the Decline of Religion in the United States (Doctoral dissertation, Duke University).

2. Voas, D., \& Chaves, M. (2016). Is the United States a counterexample to the secularization thesis?. American Journal of Sociology, 121(5), 1517-1556.

3. Bradshaw, M., \& Ellison, C. G. (2008). Do genetic factors influence religious life? Findings from a behavior genetic analysis of twin siblings. Journal for the Scientific Study of Religion, 47(4), 529-544. 
4. Koenig, L. B., McGue, M., Krueger, R. F., \& Bouchard Jr, T. J. (2005). Genetic and environmental influences on religiousness: Findings for retrospective and current religiousness ratings. Journal of personality, 73(2), 471-488.

5. Adrian-Kalchhauser, I., Sultan, S. E., Shama, L. N., Spence-Jones, H., Tiso, S., Valsecchi, C. I. K., \& Weissing, F. J. (2020). Understanding'Non-genetic'inheritance: insights from molecular-evolutionary crosstalk. Trends in ecology \& evolution.

6. Golding, J., Pembrey, M., Iles-Caven, Y., Watkins, S., Suderman, M., \& Northstone, K. (2021). Ancestral smoking and developmental outcomes: A review of publications from a population birth cohort. Biology of Reproduction, Special Issue Beyond Genes 2021; ioab124 Pub 23.6.21. https://doi.org/10.1093/biolre/ioab124

7. Svanes, C., Bertelsen, R. J., Accordini, S., Holloway, J. W., Juliusson, P., Boateng, E., ... $\&$ Skulstad, S. M. (2021). Exposures during the pre-puberty period and future offspring health: Evidence from human cohort studies. Biology of Reproduction.

8. Golding, J., Ellis, G., Gregory, S., Birmingham, K., Iles-Caven, Y., Rai, D., \& Pembrey, M. (2017). Grand-maternal smoking in pregnancy and grandchild's autistic traits and diagnosed autism. Scientific reports, 7(1), 1-14.

9. Accordini S, Johannessen A, Calciano L, Jögi R, Rovira JM, Benediktsdóttir B, Bertelsen RJ, Bråbäck L, Dharmage S, Real FG \& Holm M. Three-generation effects of tobacco smoking on lung function within the paternal line. Eur Respir J 2017;50(suppl 61): PA1178.

10. Golding, J., Gregory, S., Northstone, K., Iles-Caven, Y., Ellis, G.L. \& Pembrey, M.E. Investigating possible trans/intergenerational associations with obesity in young adults using an exposome approach. Front. Genet. 10, 314 (2019).

11. Cirillo, P. M., La Merrill, M. A., Krigbaum, N. Y., \& Cohn, B. A. (2021). Grandmaternal Perinatal Serum DDT in Relation to Granddaughter Early Menarche and Adult Obesity: Three Generations in the Child Health and Development Studies Cohort. Cancer Epidemiology and Prevention Biomarkers.

12. Pembrey, M.E., Bygren, L.O., Kaati, G., Edvinsson, S., Northstone, K., Sjostrom, M., et al. Sex-specific, male-line transgenerational responses in humans. Eur. J. Hum. Genet. 14, 159 (2006).

13. van den Berg, G.J. \& Pinger, P.R. Transgenerational effects of childhood conditions on third generation health and education outcomes. Econ. Hum. Biol. 23, 103-120. (2016).

14. Bygren LO, Kaati G \& Edvinsson S. Longevity determined by paternal ancestors' nutrition during their slow growth period. Acta Biotheor 2001; 49(1): 53-59.

15. Iles-Caven Y, Gregory S, Northstone K and Golding J. Longitudinal data on parental religious behaviour and beliefs from the Avon Longitudinal Study of Parents and Children (ALSPAC) [version 2; peer review: 2 approved] Wellcome Open Research 2019, 4:38 (https://doi.org/10.12688/wellcomeopenres.15127.2)

16. Vågerö D, Pinger PR, Aronsson V \& van den Berg GJ. Paternal grandfather's access to food predicts all-cause and cancer mortality in grandsons. Nat Commun 2018; 9(1):1-7 
17. Golding, J., Gregory, S., Matthews, S., Smith, D., Suarez-Perez, A., Bowring, C., et al. Ancestral childhood environmental exposures occurring to the grandparents and greatgrandparents of the ALSPAC study children. Wellcome Open Res. 5, (2020).

18. Watkins SH, Iles-Caven Y, Pembrey M, Golding J, Suderman M. Grandmaternal smoking during pregnancy is associated with differential DNA methylation in their grandchildren. bioRxiv, 2021.2004.2022.440892. doi:10.1101/2021.04.22.440892

19. Hayward, R. D., Owen, A. D., Koenig, H. G., Steffens, D. C., \& Payne, M. E. (2011). Associations of religious behavior and experiences with extent of regional atrophy in the orbitofrontal cortex during older adulthood. Religion, brain \& behavior, 1(2), 103-118.

20. Rim, J. I., Ojeda, J. C., Svob, C., Kayser, J., Drews, E., Kim, Y., ... \& Weissman, M. M. (2019). Current understanding of religion, spirituality, and their neurobiological correlates. Harvard review of psychiatry, 27(5), 303.

21.Ferguson MA, Schaper FL, Cohen A, Siddiqi S, Merrill SM, Nielsen JA, Grafman J, Urgesi C, Fabbro F, Fox MD. A neural circuit for spirituality and religiosity derived from patients with brain lesions. Biological Psychiatry. 2021 Jun 29.

22. Skinner, M. K. (2014). Environmental stress and epigenetic transgenerational inheritance. BMC medicine, 12(1), 1-5.

23. Yehuda R, Daskalakis NP, Bierer LM, Bader HN, Klengel T, Holsboer F, Binder EB. Holocaust exposure induced intergenerational effects on FKBP5 methylation. Biological psychiatry. 2016 Sep 1;80(5):372-80.

24. Bierer LM, Bader HN, Daskalakis NP, Lehrner A, Provençal N, Wiechmann T, Klengel T, Makotkine I, Binder EB, Yehuda R. Intergenerational effects of maternal holocaust exposure on FKBP5 Methylation. American Journal of Psychiatry. 2020 Aug 1;177(8):74453.

25. Stenz, L., Schechter, D. S., Serpa, S. R., \& Paoloni-Giacobino, A. (2018).

Intergenerational transmission of DNA methylation signatures associated with early life stress. Current genomics, 19(8), 665-675.

26. Serpeloni F, Radtke K, De Assis SG, Henning F, Nätt D, Elbert T. Grandmaternal stress during pregnancy and DNA methylation of the third generation: an epigenome-wide association study. Translational psychiatry. 2017 Aug;7(8):e1202-.

27. Golding, J., Pembrey, M., \& Jones, R. ALSPAC--the Avon Longitudinal Study of Parents and Children. I. Study methodology. Paediatr. Perinatal Epidemiol. 15(1), 74-87 (2001).

28. Boyd, A., Golding, J., Macleod, J., Lawlor, D. A., Fraser, A., Henderson, J., et al. Cohort profile: the 'children of the 90s' - the index offspring of the Avon Longitudinal Study of Parents and Children. Int. J. Epidemiol. 42(1), 111-127 (2013).

29. Fraser, A., Macdonald-Wallis, C., Tilling, K., Boyd, A., Golding, J., Davey Smith, G., et al. Cohort profile: the Avon Longitudinal Study of Parents and Children: ALSPAC mothers cohort. Int. J. Epidemiol. 42(1), 97-110 (2013).

30. Northstone, K., Lewcock, M., Groom, A., Boyd, A., Macleod, J., Timpson, N.J., et al. The Avon Longitudinal Study of Parents and Children (ALSPAC): an updated on the 
enrolled sample of index children in 2019. Wellcome Open Res. 4, 51 (2019)

(https://doi.org/10.12688/wellcomeopenres.15132.1)

32. Harris, P.A., Taylor, R., Thielke, R., Payne, J., Gonzalez, N., \& Conde, J.G. Research electronic data capture (REDCap) - A metadata-driven methodology and workflow process for providing translational research informatics support. J. Biomed. Inform. 42(2), 377-381 2009).

33. Birmingham, K. Pioneering Ethics in a Longitudinal Study: The Early Development of the ALSPAC Ethics and Law Committee. (Public Policy Press, Bristol, 2018). 
Figure 1. The final models: features of the grandparents independently associated with the index woman's religious belief

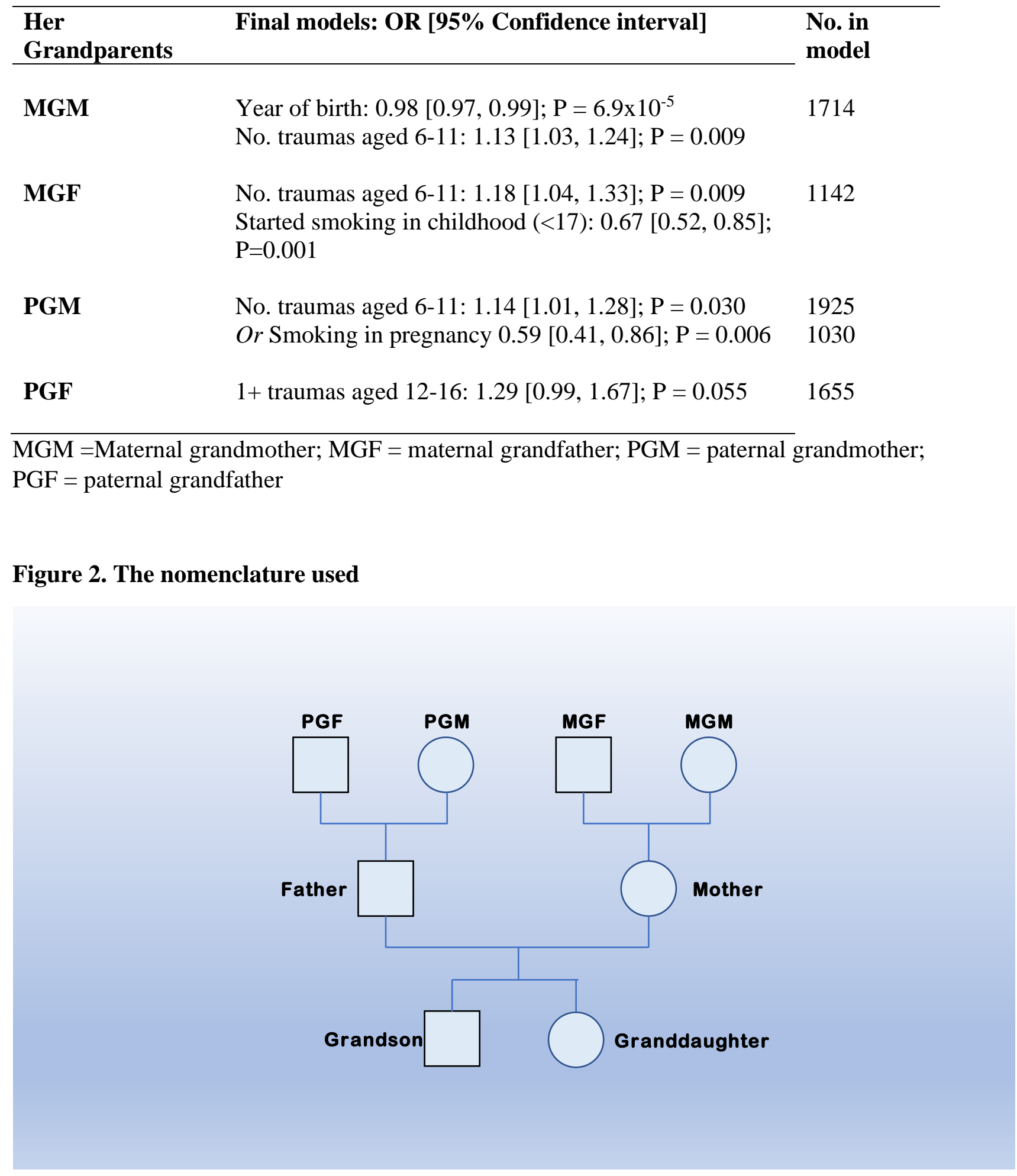

MGM =Maternal grandmother; $\mathrm{MGF}=$ maternal grandfather; $\mathrm{PGM}=$ paternal grandmother; $\mathrm{PGF}=$ paternal grandfather 
Table 1. Proportion (n) of granddaughters with a religious belief according to the demographic features of their grandparents (in bold are values of $P<0.05$ ).

\begin{tabular}{|c|c|c|c|c|}
\hline $\begin{array}{l}\text { Demographic features } \\
\text { of grandparents }\end{array}$ & MGM & MGF & PGM & PGF \\
\hline \multicolumn{5}{|l|}{ Born in England } \\
\hline Yes & $54.0(1267)$ & $55.4(1100)$ & $54.8(999)$ & $56.1(905)$ \\
\hline No & $57.9(327)$ & $57.3(271)$ & $54.9(246)$ & $55.3(210)$ \\
\hline $\mathrm{P}$ & 0.099 & 0.460 & 0.957 & 0.775 \\
\hline \multicolumn{5}{|l|}{ Year of birth } \\
\hline Pre 1890 & $65.2(90)$ & $61.8(123)$ & $58.0(98)$ & $56.3(130)$ \\
\hline 1890-1899 & $58.4(216)$ & $56.6(196)$ & $53.1(173)$ & $51.7(163)$ \\
\hline 1900-1909 & $58.2(407)$ & $59.5(331)$ & $59.5(290)$ & $62.3(240)$ \\
\hline $1910+$ & $50.7(308)$ & $51.7(180)$ & $52.1(149)$ & $52.4(87)$ \\
\hline $\mathrm{P}_{\mathrm{A}}$ & 0.003 & 0.063 & 0.130 & 0.025 \\
\hline $\mathrm{P}^{*}$ & $<0.001$ & 0.062 & 0.849 & 0.410 \\
\hline \multicolumn{5}{|l|}{ Social Class } \\
\hline Non-manual & $59.1(306)$ & $58.4(432)$ & $55.3(218)$ & $55.8(343)$ \\
\hline Manual & $55.4(506)$ & $56.3(629)$ & $54.1(309)$ & $57.5(499)$ \\
\hline $\mathrm{P}$ & 0.173 & 0.378 & 0.710 & 0.511 \\
\hline \multicolumn{5}{|l|}{$\begin{array}{l}\text { Age at birth of next } \\
\text { generation }\end{array}$} \\
\hline$<25$ & $52.6(215)$ & $50.3(87)$ & $56.9(132)$ & $56.1(60)$ \\
\hline $25-34$ & $56.1(578)$ & $57.8(472)$ & $56.4(425)$ & $57.7(344)$ \\
\hline $35-39$ & $60.5(208)$ & $58.6(150)$ & $53.3(131)$ & $55.5(121)$ \\
\hline $40+$ & $\mathrm{X}$ & $60.5(115)$ & $X$ & $52.0(79)$ \\
\hline $\mathrm{P}$ & 0.030 & 0.089 & 0.416 & 0.290 \\
\hline $\mathrm{P} * *$ & 0.023 & 0.341 & 0.295 & 0.232 \\
\hline \multicolumn{5}{|l|}{ Was firstborn } \\
\hline Yes & $58.1(264)$ & $55.2(174)$ & $58.2(181)$ & $58.7(158)$ \\
\hline No & $56.3(599)$ & $58.4(445)$ & $55.7(390)$ & $57.3(324)$ \\
\hline $\mathrm{P}$ & 0.581 & 0.340 & 0.462 & 0.704 \\
\hline \multicolumn{5}{|l|}{ No. brothers } \\
\hline 0 & 55.4 (174) & $59.2(100)$ & $53.6(125)$ & $55.8(77)$ \\
\hline 1 & $56.1(254)$ & $53.8(205)$ & $53.5(177)$ & $58.7(165)$ \\
\hline $2+$ & $59.0(461)$ & $59.2(324)$ & $58.5(271)$ & $57.1(248)$ \\
\hline $\mathrm{P}$ & 0.228 & 0.544 & 0.161 & 0.928 \\
\hline \multicolumn{5}{|l|}{ No. sisters } \\
\hline 0 & $54.6(149)$ & $50.5(97)$ & $56.1(97)$ & $54.4(92)$ \\
\hline 1 & $57.7(290)$ & $55.2(206)$ & $56.1(201)$ & $59.7(154)$ \\
\hline $2+$ & $57.2(455)$ & $60.3(323)$ & $54.6(281)$ & $56.9(246)$ \\
\hline $\mathrm{P}$ & 0.563 & 0.014 & 0.656 & 0.766 \\
\hline
\end{tabular}

MGM =Maternal grandmother; MGF = maternal grandfather; $\mathrm{PGM}=$ paternal grandmother; $\mathrm{PGF}=$ paternal grandfather; $\mathrm{X}=$ category combined with preceding one; $* \mathrm{P}$ for linear trend with year of birth of grandparent; **P for trend with actual age at which the grandparent became a parent 
Table 2. Proportion (n) of granddaughters with a religious belief according to the environmental exposures of their grandparents (in bold are values of $P<0.05$ ).

\begin{tabular}{|c|c|c|c|c|}
\hline Environmental exposures & MGM & MGF & PGM & PGF \\
\hline \multicolumn{5}{|l|}{ No. of traumatic events $<6 y$} \\
\hline 0 & $55.4(1258)$ & $56.0(1066)$ & $55.6(955)$ & $56.5(836)$ \\
\hline 1 & $47.4(91)$ & $56.0(70)$ & $50.0(48)$ & $59.8(52)$ \\
\hline 2 & $49.4(40)$ & $59.6(31)$ & $50.0(16)$ & $50.0(15)$ \\
\hline $3+$ & $61.4(94)$ & $59.6(65)$ & $53.8(49)$ & $53.4(31)$ \\
\hline $\mathrm{P}$ & 0.042 & 0.412 & 0.488 & 0.631 \\
\hline $\mathrm{P}[0 \vee 1+]$ & 0.318 & 0.526 & 0.268 & 0.902 \\
\hline \multicolumn{5}{|l|}{ No. of traumatic events $6-11 y$} \\
\hline 0 & $54.3(1202)$ & $54.5(994)$ & $54.0(896)$ & $56.7(820)$ \\
\hline 1 & $53.8(126)$ & $65.3(111)$ & $61.2(85)$ & $55.6(55)$ \\
\hline 2 & $55.3(47)$ & $70.2(40)$ & $61.2(30)$ & $47.5(19)$ \\
\hline $3+$ & $66.7(108)$ & $63.0(87)$ & $63.3(57)$ & $56.3(40)$ \\
\hline $\mathrm{P}$ & 0.009 & 0.002 & 0.021 & 0.559 \\
\hline $\mathrm{P}[0 \vee 1+]$ & 0.099 & $<0.001$ & 0.015 & 0.502 \\
\hline \multicolumn{5}{|c|}{ No. of traumatic events $12-16 y$} \\
\hline 0 & $54.1(1166)$ & $55.1(977)$ & $54.4(856)$ & $55.4(755)$ \\
\hline 1 & $57.2(147)$ & $63.2(115)$ & $57.9(110)$ & $56.6(81)$ \\
\hline 2 & $52.5(53)$ & $55.3(47)$ & $54.5(30)$ & $68.2(30)$ \\
\hline $3+$ & $65.0(117)$ & $63.3(93)$ & $60.5(72)$ & $65.4(68)$ \\
\hline $\mathrm{P}$ & 0.013 & 0.035 & 0.175 & 0.018 \\
\hline $\mathrm{P}[0 \vee 1+]$ & 0.043 & 0.016 & 0.183 & 0.055 \\
\hline \multicolumn{5}{|l|}{ Started smoking $<17$} \\
\hline Yes & $54.0(167)$ & $53.2(405)$ & $46.8(97)$ & $56.6(325)$ \\
\hline No & $56.7(850)$ & $61.6(302)$ & $56.2(595)$ & $59.1(182)$ \\
\hline $\mathrm{P}$ & 0.384 & 0.003 & 0.014 & 0.479 \\
\hline \multicolumn{5}{|l|}{ Smoked in pregnancy } \\
\hline Yes & $58.4(125)$ & - & $45.2(57)$ & - \\
\hline No & $56.1(735)$ & & $57.6(528)$ & \\
\hline $\mathrm{P}$ & 0.521 & & 0.007 & \\
\hline
\end{tabular}

MGM =Maternal grandmother; MGF = maternal grandfather; $\mathrm{PGM}=$ paternal grandmother; $\mathrm{PGF}=$ paternal grandfather . 
Table 3. Proportion (n) of grandsons with a religious belief according to the demographic features of his grandparents (in bold are values of $\mathrm{P}<0.05$ ).

\begin{tabular}{|c|c|c|c|c|}
\hline $\begin{array}{l}\text { Demographic features } \\
\text { of grandparents }\end{array}$ & MGM & MGF & PGM & PGF \\
\hline \multicolumn{5}{|l|}{ Born in England } \\
\hline Yes & $40.5(380)$ & $40.3(340)$ & $41.5(337)$ & $43.1(338)$ \\
\hline No & $46.9(115)$ & $45.8(97)$ & $43.5(84)$ & $40.9(72)$ \\
\hline $\mathrm{P}$ & 0.068 & 0.149 & 0.600 & 0.603 \\
\hline \multicolumn{5}{|l|}{ Year of birth } \\
\hline Pre 1890 & $36.9(38)$ & $42.5(57)$ & $37.0(44)$ & $40.8(73)$ \\
\hline 1890-1899 & $44.2(88)$ & $43.0(92)$ & $41.1(78)$ & $45.0(87)$ \\
\hline 1900-1909 & $44.9(128)$ & $45.8(93)$ & $44.1(94)$ & $43.5(73)$ \\
\hline $1910+$ & $33.8(49)$ & $29.0(27)$ & $42.5(31)$ & $30.6(15)$ \\
\hline $\mathrm{P}$ & 0.094 & 0.056 & 0.648 & 0.314 \\
\hline $\mathrm{P}^{*}$ & 0.449 & 0.105 & 0.280 & 0.169 \\
\hline \multicolumn{5}{|l|}{ Social Class } \\
\hline Non-manual & $41.1(85)$ & $40.4(147)$ & $47.0(70)$ & $43.4(144)$ \\
\hline Manual & $39.9(113)$ & $40.3(196)$ & $43.0(89)$ & $41.2(193)$ \\
\hline $\mathrm{P}$ & 0.801 & 0.987 & 0.456 & 0.530 \\
\hline \multicolumn{5}{|l|}{ Age at birth of next } \\
\hline \multicolumn{5}{|l|}{ Generation } \\
\hline$<25$ & $40.1(57)$ & $41.7(25)$ & $41.0(50)$ & $36.1(22)$ \\
\hline $25-34$ & $41.5(181)$ & $38.2(138)$ & $41.8(142)$ & $40.9(135)$ \\
\hline $35-39$ & $42.4(59)$ & $43.7(52)$ & $40.2(49)$ & $44.6(45)$ \\
\hline $40+$ & $\mathrm{X}$ & $51.5(50)$ & $\mathrm{X}$ & $48.3(43)$ \\
\hline $\mathrm{P}$ & 0.695 & 0.042 & 0.897 & 0.099 \\
\hline $\mathrm{P} * *$ & 0.190 & 0.008 & 0.959 & 0.042 \\
\hline \multicolumn{5}{|l|}{ Was firstborn } \\
\hline Yes & $43.4(56)$ & $48.6(54)$ & $43.7(52)$ & $44.0(51)$ \\
\hline No & $42.7(165)$ & $42.8(128)$ & $38.6(98)$ & 41.1 (109) \\
\hline $\mathrm{P}$ & 0.660 & 0.272 & 0.995 & 0.144 \\
\hline \multicolumn{5}{|l|}{ No. brothers } \\
\hline 0 & $44.3(43)$ & $45.7(32)$ & $32.1(26)$ & $41.9(18)$ \\
\hline 1 & $37.8(62)$ & $40.3(48)$ & $47.5(56)$ & $43.4(63)$ \\
\hline $2+$ & $46.3(118)$ & 43.8 (102) & $40.2(68)$ & $44.2(87)$ \\
\hline $\mathrm{P}$ & 0.437 & 0.969 & 0.410 & 0.265 \\
\hline \multicolumn{5}{|l|}{ No. sisters } \\
\hline 0 & $44.3(35)$ & $48.6(35)$ & $42.6(29)$ & $51.2(44)$ \\
\hline 1 & $44.6(74)$ & $45.5(61)$ & $36.2(46)$ & $41.7(55)$ \\
\hline $2+$ & $42.6(116)$ & $41.4(87)$ & $41.6(72)$ & $40.5(70)$ \\
\hline $\mathrm{P}$ & 0.718 & 0.254 & 0.882 & 0.131 \\
\hline
\end{tabular}

MGM =Maternal grandmother; $\mathrm{MGF}=$ maternal grandfather; $\mathrm{PGM}=$ paternal grandmother; $\mathrm{PGF}=$ paternal grandfather; $* \mathrm{P}$ for linear trend with year of birth of grandparent; **P for trend with actual age at which the grandparent became a parent 
Table 4. Proportion (n) of grandsons with a religious belief according to the environmental exposures of his grandparents (in bold are values of $\mathrm{P}<0.05$ ).

\begin{tabular}{|c|c|c|c|c|}
\hline Environmental Exposure & MGM & MGF & PGM & PGF \\
\hline \multicolumn{5}{|l|}{ No. of events before age $6 y$} \\
\hline 0 & $43.1(405)$ & $42.0(338)$ & $42.3(303)$ & $43.2(311)$ \\
\hline 1 & $25.4(17)$ & $45.0(18)$ & $52.4(22)$ & $38.5(15)$ \\
\hline $2+$ & $33.3(17)$ & $18.6(8)$ & $37.8(14)$ & $24.0(6)$ \\
\hline $\mathrm{P}$ & 0.018 & 0.010 & 0.923 & 0.046 \\
\hline$P[0 \vee 1+]$ & 0.003 & 0.061 & 0.572 & 0.110 \\
\hline \multicolumn{5}{|l|}{ No. of events aged 6-11 } \\
\hline 0 & $41.8(380)$ & $41.9(321)$ & $42.4(293)$ & $42.6(297)$ \\
\hline 1 & $40.0(34)$ & $35.5(22)$ & $37.3(22)$ & $40.7(22)$ \\
\hline $2+$ & $39.7(25)$ & $36.2(21)$ & $52.2(24)$ & $39.4(13)$ \\
\hline $\mathrm{P}$ & 0.856 & 0.354 & 0.309 & 0.509 \\
\hline$P[0 \vee 1+]$ & 0.665 & 0.214 & 0.786 & 0.672 \\
\hline \multicolumn{5}{|l|}{ No. of events aged 12-16 } \\
\hline 0 & $41.6(341)$ & $40.1(280)$ & $43.1(275)$ & $42.4(263)$ \\
\hline 1 & $37.7(46)$ & $43.9(43)$ & $37.0(30)$ & $44.7(42)$ \\
\hline 2 & $40.8(20)$ & $28.6(8)$ & $42.3(11)$ & $35.3(6)$ \\
\hline $3+$ & $47.8(32)$ & $53.2(33)$ & $45.1(23)$ & $40.4(21)$ \\
\hline $\mathrm{P}$ & 0.589 & 0.138 & 0.944 & 0.774 \\
\hline$P[0 \vee 1+]$ & 0.910 & 0.253 & 0.555 & 0.996 \\
\hline \multicolumn{5}{|l|}{ Started smoking $<17$} \\
\hline Yes & $37.5(39)$ & $39.9(114)$ & $37.0(27)$ & $38.1(82)$ \\
\hline No & $43.8(224)$ & $47.3(88)$ & $42.5(167)$ & $47.5(66)$ \\
\hline $\mathrm{P}$ & 0.235 & 0.110 & 0.381 & 0.082 \\
\hline \multicolumn{5}{|l|}{ Smoked in pregnancy } \\
\hline Yes & $34.4(22)$ & - & $38.1(16)$ & - \\
\hline No & $43.5(204)$ & & $44.1(158)$ & \\
\hline $\mathrm{P}$ & 0.168 & & 0.456 & \\
\hline
\end{tabular}

$\mathrm{MGM}=$ Maternal grandmother; $\mathrm{MGF}=$ maternal grandfather; $\mathrm{PGM}=$ paternal grandmother; $\mathrm{PGF}=$ paternal grandfather. 
Table 5. List of traumatic events occurring to grandparents which showed a difference between the religious beliefs of their grandchildren (the index women and index men) at $\mathbf{P}<\mathbf{0 . 1 0}$.

\begin{tabular}{|c|c|c|c|c|}
\hline Grandparent & Age & Event & OR [95\% CI] & $\mathbf{P}$ \\
\hline \multirow{7}{*}{ MGM } & & & Granddaughter & \\
\hline & $<6$ & Seriously ill & $0.53[0.26,1.08]$ & 0.082 \\
\hline & $6-11$ & Taken into care & $2.37[0.86,6.54]$ & 0.096 \\
\hline & & Mother in war situation & $1.63[1.16,2.30]$ & 0.005 \\
\hline & & Father in war situation & $1.39[0.99,1.96]$ & 0.060 \\
\hline & $12-16$ & In a war situation & $1.26[0.99,1.61]$ & 0.059 \\
\hline & & Mother seriously ill & $2.11[0.98,4.54]$ & 0.056 \\
\hline \multirow[t]{4}{*}{ MGF } & $6-11$ & In a war situation & $1.32[0.99,1.77]$ & 0.059 \\
\hline & & Mother died & $4.40[1.29,15.0]$ & 0.018 \\
\hline & $12-16$ & Father died & $0.43[0.19,1.01]$ & 0.054 \\
\hline & & Was unhappy & $2.55[0.94,6.87]$ & 0.065 \\
\hline \multirow[t]{2}{*}{ PGM } & $6-11$ & Mother died & $2.26[1.04,4.91]$ & 0.039 \\
\hline & & In war situation & $1.60[1.15,2.23]$ & 0.005 \\
\hline \multirow[t]{4}{*}{ PGF } & $12-16$ & In war situation & $1.51[1.11,2.05]$ & 0.009 \\
\hline & & Mother in war situation & $1.71[1.11,2.63]$ & 0.014 \\
\hline & & Father in war situation & $1.85[1.18,2.91]$ & 0.007 \\
\hline & & & Grandsons & \\
\hline \multirow[t]{4}{*}{ MGM } & $<6$ & Insufficient food & $0.41[0.18,0.94]$ & 0.034 \\
\hline & & In war situation & $0.51[0.28,0.93]$ & 0.029 \\
\hline & $6-11$ & Insufficient food & $0.52[0.25,1.08]$ & 0.079 \\
\hline & $12-16$ & Moved to new location & $0.33[0.12,0.88]$ & 0.027 \\
\hline \multirow[t]{6}{*}{ MGF } & $<6$ & In war situation & $0.31[0.14,0.72]$ & 0.006 \\
\hline & & Mother in war situation & $0.28[0.09,0.82]$ & 0.021 \\
\hline & & Father in war situation & $0.24[0.08,0.72]$ & 0.010 \\
\hline & $6-11$ & Insufficient food & $0.42[0.16,1.08]$ & 0.071 \\
\hline & $12-16$ & Mother in war situation & $1.60[0.96,2.66]$ & 0.071 \\
\hline & & Father in war situation & $2.04[1.19,3.50]$ & 0.010 \\
\hline PGM & $6-11$ & In war situation & $2.00[0.93,4.30]$ & 0.076 \\
\hline \multirow[t]{3}{*}{ PGF } & $<6$ & Insufficient food & $0.25[0.07,0.88]$ & 0.031 \\
\hline & $6-11$ & Insufficient food & $0.29[0.10,0.88]$ & 0.029 \\
\hline & $12-16$ & Insufficient food & $0.44[0.17,1.15]$ & 0.094 \\
\hline
\end{tabular}

MGM =Maternal grandmother; MGF = maternal grandfather; $\mathrm{PGM}=$ paternal grandmother; $\mathrm{PGF}=$ paternal grandfather. The OR gives the odds ratio of the index participants having a religious belief together with the $95 \%$ CI (confidence interval). 
Table 6. Summary of sex specific differences concerning the associations between grandmother smoking during pregnancy and adjusted outcomes to the grandchild (adapted from [6])

\begin{tabular}{llll}
\hline Grandmother & $\begin{array}{l}\text { Grandchild outcome } \\
\text { analysed }\end{array}$ & Grandson & Granddaughter \\
\hline \multirow{2}{*}{ Maternal (MGM) } & $\begin{array}{l}\text { Fetal growth } \\
\text { Lean mass }\end{array}$ & $\begin{array}{l}\text { Greater } \\
\text { Greater }\end{array}$ & - \\
& Strength and fitness & Greater & - \\
& Autistic traits & - & Increased \\
& Myopia by 7 & Greatly reduced & Reduced \\
& Sensitivity to noise & More sensitive & Less sensitive \\
& & & \\
Paternal (PGM) & Height & - & Taller \\
& Fat mass & - & Increased \\
& Verbal IQ & Reduced & - \\
& Persistent wheeze & - & Greater \\
& Diagnosed asthma & - & Greater \\
& Extreme taster & - & Greater \\
& Religious belief & - & Reduced \\
& & & \\
\hline
\end{tabular}


Supplementary Table 1. Control analysis: Proportion (n) of index women with a religious belief according to the demographic features of her partner's grandparents (in bold are values of $\mathrm{P}<0.05)$.

\begin{tabular}{|c|c|c|c|c|}
\hline $\begin{array}{l}\text { Demographic features } \\
\text { of partners' grandparents }\end{array}$ & $\begin{array}{l}\text { Partner's } \\
\text { MGM } \\
\end{array}$ & $\begin{array}{l}\text { Partner's } \\
\text { MGF } \\
\end{array}$ & $\begin{array}{l}\text { Partner's } \\
\text { PGM } \\
\end{array}$ & $\begin{array}{l}\text { Partner's } \\
\text { PGF } \\
\end{array}$ \\
\hline \multicolumn{5}{|l|}{ Born in England } \\
\hline Yes & $56.4(560)$ & $56.1(499)$ & $55.5(474)$ & $56.9(469)$ \\
\hline No & $56.7(148)$ & 56.9 (128) & $58.5(121)$ & $56.3(107)$ \\
\hline $\mathrm{P}$ & 0.928 & 0.838 & 0.443 & 0.880 \\
\hline \multicolumn{5}{|l|}{ Year of birth } \\
\hline Pre 1890 & $43.0(46)$ & $48.2(67)$ & $52.7(68)$ & $56.8(109)$ \\
\hline 1890-1899 & $58.9(123)$ & $59.8(134)$ & $58.5(117)$ & $62.7(126)$ \\
\hline 1900-1909 & $61.0(183)$ & $65.6(139)$ & $61.5(136)$ & $55.6(99)$ \\
\hline $1910+$ & $54.5(84)$ & $48.0(48)$ & $54.4(43)$ & $51.0(26)$ \\
\hline $\mathrm{P}$ & 0.012 & 0.002 & 0.386 & 0.340 \\
\hline $\mathrm{P}^{*}$ & 0.100 & 0.222 & 0.535 & 0.538 \\
\hline \multicolumn{5}{|l|}{ Social Class } \\
\hline Non-manual & $55.6(120)$ & $56.7(217)$ & $57.1(89)$ & $60.6(209)$ \\
\hline Manual & $54.7(162)$ & $58.2(298)$ & $57.5(127)$ & $55.1(274)$ \\
\hline $\mathrm{P}$ & 0.853 & 0.644 & 0.936 & 0.116 \\
\hline \multicolumn{5}{|l|}{ Age at birth of next } \\
\hline \multicolumn{5}{|l|}{ Generation } \\
\hline$<25$ & $55.3(84)$ & $56.5(35)$ & $57.4(74)$ & $63.9(39)$ \\
\hline $25-34$ & $58.2(266)$ & $60.9(231)$ & $56.8(204)$ & $53.7(191)$ \\
\hline $35-39$ & $52.1(75)$ & $47.6(59)$ & $59.5(78)$ & $59.4(60)$ \\
\hline $40+$ & $X$ & $56.9(58)$ & $X$ & $67.7(65)$ \\
\hline $\mathrm{P}$ & 0.599 & 0.244 & 0.721 & 0.111 \\
\hline $\mathrm{P} * *$ & 0.267 & 0.406 & 0.934 & 0.178 \\
\hline \multicolumn{5}{|l|}{ Was firstborn } \\
\hline Yes & $51.9(70)$ & $58.0(69)$ & $56.5(70)$ & $58.4(73)$ \\
\hline No & 57.7 (236) & $57.8(182)$ & $57.1(153)$ & $55.1(151)$ \\
\hline $\mathrm{P}$ & 0.234 & 0.969 & 0.906 & 0.539 \\
\hline \multicolumn{5}{|l|}{ No. brothers } \\
\hline 0 & $53.1(51)$ & $52.7(39)$ & $48.8(40)$ & $49.2(27)$ \\
\hline 1 & $56.2(100)$ & $55.5(71)$ & $59.2(74)$ & $58.7(88)$ \\
\hline $2+$ & $58.1(158)$ & $60.2(147)$ & $58.8(107)$ & 57.7 (120) \\
\hline $\mathrm{P}$ & 0.398 & 0.202 & 0.183 & 0.348 \\
\hline \multicolumn{5}{|l|}{ No. sisters } \\
\hline 0 & $55.2(48)$ & $64.6(51)$ & $55.1(38)$ & $56.0(51)$ \\
\hline 1 & $55.7(97)$ & $60.1(83)$ & $54.8(74)$ & $52.6(71)$ \\
\hline $2+$ & $59.6(170)$ & $55.4(124)$ & 59.8 (110) & $58.4(108$ \\
\hline $\mathrm{P}$ & 0.364 & 0.134 & 0.397 & 0.579 \\
\hline
\end{tabular}

MGM =Maternal grandmother; MGF = maternal grandfather; PGM = paternal grandmother; $\mathrm{PGF}=$ paternal grandfather; $\mathrm{X}=$ category combined with preceding one; $* \mathrm{P}$ for linear trend with year of birth of grandparent; **P for trend with actual age at which the grandparent became a parent 
Supplementary Table 2. Control analyses: Proportion (n) of index women with a religious belief according to the potential epigenetic features of her partner's grandparents (in bold are values of $\mathrm{P}<0.05$ ).

\begin{tabular}{|c|c|c|c|c|}
\hline Exposures to grandparents & $\begin{array}{l}\text { Partner's } \\
\text { MGM }\end{array}$ & $\begin{array}{l}\text { Partner's } \\
\text { MGF }\end{array}$ & $\begin{array}{l}\text { Partner's } \\
\text { PGM }\end{array}$ & $\begin{array}{l}\text { Partner's } \\
\text { PGF }\end{array}$ \\
\hline \multicolumn{5}{|l|}{ No. of events before age $6 y$} \\
\hline 0 & $58.4(576)$ & $57.7(489)$ & $56.4(429)$ & $55.7(424)$ \\
\hline 1 & $50.7(36)$ & $51.2(21)$ & $59.5(25)$ & $55.0(22)$ \\
\hline 2 & $25.0(5)$ & $64.3(9)$ & $57.1(8)$ & $70.0(7)$ \\
\hline $3+$ & $60.0(21)$ & $50.0(15)$ & $54.2(13)$ & $58.8(10)$ \\
\hline $\mathrm{P}$ & 0.028 & 0.437 & 0.972 & 0.592 \\
\hline $\mathrm{P}[0 \vee 1+]$ & 0.051 & 0.395 & 0.857 & 0.694 \\
\hline \multicolumn{5}{|l|}{ No. of events aged 6-11 } \\
\hline 0 & $56.9(547)$ & $58.3(473)$ & $56.6(414)$ & $56.2(414)$ \\
\hline 1 & $62.1(54)$ & $50.8(31)$ & $59.3(35)$ & $56.9(33)$ \\
\hline 2 & $59.0(13)$ & $42.3(11)$ & $35.7(5)$ & $50.0(7)$ \\
\hline $3+$ & $55.8(24)$ & $57.5(19)$ & $60.0(21)$ & $47.4(9)$ \\
\hline $\mathrm{P}$ & 0.789 & 0.256 & 0.953 & 0.458 \\
\hline $\mathrm{P}[0 \vee 1+]$ & 0.495 & 0.126 & 0.988 & 0.673 \\
\hline \multicolumn{5}{|l|}{ No. of events aged 12-16 } \\
\hline 0 & $57.1(495)$ & $57.5(424)$ & $57.5(389)$ & $55.9(368)$ \\
\hline 1 & $65.3(81)$ & $58.8(60)$ & $51.2(42)$ & $60.2(59)$ \\
\hline 2 & $56.9(29)$ & $57.1(16)$ & $51.9(14)$ & $11.1(5)$ \\
\hline $3+$ & $46.5(33)$ & $53.1(34)$ & $54.5(30)$ & $57.4(31)$ \\
\hline $\mathrm{P}$ & 0.328 & 0.607 & 0.392 & 0.763 \\
\hline $\mathrm{P}[0 \vee 1+]$ & 0.772 & 0.851 & 0.237 & 0.992 \\
\hline \multicolumn{5}{|l|}{ Started smoking $<17$} \\
\hline Yes & $57.9(62)$ & $54.2(161)$ & $57.1(44)$ & $54.2(123)$ \\
\hline No & $54.6(290)$ & $56.9(111)$ & $54.9(229)$ & $53.4(79)$ \\
\hline $\mathrm{P}$ & 0.528 & 0.554 & 0.718 & 0.878 \\
\hline \multicolumn{5}{|l|}{ Smoked in pregnancy } \\
\hline Yes & $49.2(32)$ & - & $59.1(26)$ & - \\
\hline No & $55.6(270)$ & & $55.0(209)$ & \\
\hline $\mathrm{P}$ & 0.337 & & 0.606 & \\
\hline
\end{tabular}

MGM =Maternal grandmother; $\mathrm{MGF}=$ maternal grandfather; $\mathrm{PGM}=$ paternal grandmother; $\mathrm{PGF}=$ paternal grandfather. 
Supplementary Table 3. Numbers of women and men with data on religious belief together with features concerning the grandparents.

\begin{tabular}{lrrrr}
\hline Feature of grandparents & MGM & MGF & PGM & PGF \\
\hline$\quad$ INDEX WOMEN & & & & \\
Demographic factors & & & & \\
Year of birth, age & 1814 & 1451 & 770 & 675 \\
Place of birth & 2910 & 2458 & 1254 & 1114 \\
Social class & 1432 & 1857 & 512 & 895 \\
Family structure & 1572 & 1101 & 546 & 441 \\
Possible epigenetic factors & & & & \\
Traumatic events in childhood & 1873 & 1402 & 756 & 588 \\
Onset of regular smoking & 1807 & 1251 & 638 & 492 \\
Smoking in pregnancy & 1525 & NA & 551 & NA \\
$\quad$ INDEX MEN & & & & \\
Demographic factors & & & & \\
Year of birth, age & 732 & 644 & 595 & 589 \\
Place of birth & 1184 & 1056 & 1006 & 961 \\
Social class & 490 & 850 & 356 & 801 \\
Family structure & 517 & 416 & 368 & 391 \\
Possible epigenetic factors & & & & \\
Traumatic events in childhood & 711 & 548 & 548 & 513 \\
Onset of regular smoking & 615 & 472 & 466 & 354 \\
Smoking in pregnancy & 533 & NA & 400 & NA \\
\hline MGM =
\end{tabular}

MGM = Maternal grandmother; MGF = maternal grandfather; $\mathrm{PGM}=$ paternal grandmother; $\mathrm{PGF}=$ paternal grandfather; $\mathrm{NA}=$ not appropriate . 